\title{
LAS SUGERENCIAS DIDÁCTICAS EN UN LIBRO DE TEXTO DE ARITMÉTICA PARA LA FORMACIÓN DE MAESTROS EN LAS SECCIONES NORMALES DE COSTA RICA EN EL SIGLO XIX ${ }^{\alpha}$
}

\author{
The Didactic Suggestions into a Textbook of Arithmetic for \\ Teacher Training in Normal Sections in Costa Rica in the \\ Nineteenth Century
}

\section{Miguel Evelio Picado Alfaro ${ }^{\beta}$ y Jonathan Espinoza González}

Fecha de recepción: 24/06/2019 • Fecha de aceptación: 03/08/2019

Resumen. En este artículo se destacan las sugerencias didácticas, asociadas a conceptos y procedimientos matemáticos, identificadas en un manual de aritmética para la formación inicial de maestros en las Secciones Normales en Costa Rica en el siglo XIX. El estudio corresponde a una investigación cualitativa descriptiva basada en el análisis de libros de texto, en el marco de las investigaciones históricas en educación matemática. El análisis del contenido del libro de texto se realizó a partir de las categorías del análisis didáctico asociadas a aspectos cognitivos, de instrucción y evaluación vinculadas, en este caso, con la enseñanza de la aritmética en educación primaria. Los resultados muestran una cantidad considerable de sugerencias que promueven el aprendizaje de las operaciones aritméticas. Se identifican dos etapas en el aprendizaje: una memorística y otra de promoción de capacidades en el estudiantado. En el texto se recomienda al maestro el uso de materiales y recursos, la presentación de procedimientos que se denominan invariables y la adaptación de estrategias

\footnotetext{
${ }^{\alpha}$ Este artículo se desprende de los resultados del Proyecto SIA 0134-16 titulado «La formación matemática de los maestros y maestras en la Escuela Normal de Costa Rica: el caso de la Aritmética» y desarrollado en la Escuela de Matemática de la Universidad Nacional. Agradecemos el apoyo de la Licenciada Catalina Hernández Salazar, funcionaria de la Biblioteca Nacional de Costa Rica.

${ }^{\text {B }}$ Escuela de Matemática, Facultad de Ciencias Exactas y Naturales, Universidad Nacional. Campus Omar Dengo, Heredia, 40101, Costa Rica. miguepicado@hotmail.com (D) https://orcid.org/0000-0002-7574-0797

$\checkmark$ Escuela de Matemática, Facultad de Ciencias Exactas y Naturales, Universidad Nacional. Campus Omar Dengo, Heredia, 40101, Costa Rica. espinozaj25@gmail.com
}

Cómo citar este artículo: Picado Alfaro, Miguel Evelio y Jonathan Espinoza González. «Las sugerencias didácticas en un libro de texto de aritmética para la formación de maestros en las secciones normales de Costa Rica en el siglo XIX». Historia y Memoria de la Educación 11 (2020): 151-190 
mostradas con anterioridad. Para los procesos de evaluación de los aprendizajes se plantea la verificación de resultados, la asignación de tareas orales y escritas, con un orden aleatorio o específico.

Palabras clave: Aritmética; Secciones Normales; Análisis didáctico; Formación de maestros; Libros de texto históricos de matemáticas.

Abstract. In this article we highlight didactic suggestions linked to mathematical concepts and procedures that we identified in a manual of arithmetic for initial teacher training in the Normal Sections in Costa Rica in the 19th century. The study adopts a qualitative descriptive research based on the analysis of textbooks, within the framework of historical research in mathematics education. The content analysis of the textbook was carried out from the categories of the didactic analysis associated with the cognitive, instructional and assessment aspects linked, in this case, to teaching of arithmetic in primary education. The results highlight a considerable number of suggestions that promote the learning of arithmetic operations. We identified two stages for learning: memorization and promotion of capacities in students. In the text, teachers are encouraged to use varied materials and resources, to rely on invariable procedures and to adaptpreviously used strategies. In order to evaluate the learning processes, the text recommends verifying results and assigning oral and written tasks, either in a random or specific order.

Keywords: Arithmetic; Didactic Analysis; Normal Sections; Teacher training; Historical Textbooks of Mathematics.

Al abordar la formación de maestras y maestros en Costa Rica es imprescindible pensar en la fundación de la Escuela Normal en 1914. Como centro de estudios, esta institución marcó un punto de inflexión en cuanto a las iniciativas de la profesionalización de estas y estos educadores de la educación primaria. Sin embargo, con anterioridad a la creación de la Escuela Normal, el Estado costarricense atendía la necesidad de preparar maestras y maestros mediante la conformación de secciones o departamentos especializados para este fin en las instituciones de educación secundaria. En lo que sigue, para efectos de la lectura, nos referimos a este grupo de maestras y maestros únicamente como maestros, sin que esto desmerite el aporte de alguno de estos grupos a la educación en Costa Rica.

El estudio de las matemáticas y las peculiaridades sobre la formación de maestros en Costa Rica conducen al planteo de cuestiones diversas, como ¿qué matemáticas se abordaban en la formación de maestros en las 
Secciones Normales?, ¿qué papel tenían los textos de matemáticas en estos procesos de formación?, ¿qué elementos didácticos se sugerían a los maestros para la enseñanza de las matemáticas? o ¿qué consideraciones se presentaban a los maestros en cuanto al aprendizaje de los estudiantes? En este trabajo se responden algunas de estas preguntas tomando como fuente primordial de información el libro de texto Manual para el maestro. Curso elemental de aritmética editado en San José en 1897.

El objetivo del estudio es caracterizar las sugerencias didácticas propuestas en un libro de texto para la enseñanza de la aritmética, como parte del proceso de formación de maestros en las denominadas Secciones Normales en Costa Rica, a finales del siglo XIX. Para esto, se describen los conceptos aritméticos considerados y se analizan las indicaciones, que el autor del texto propone, para el abordaje de estos conceptos y los procedimientos aritméticos, en los primeros cuatro años de la educación primaria en la época. Para esto se implementan algunos de los principios del Análisis Didáctico, como marco metodológico para el estudio de libros de texto.

\section{LAS SECCIONES NORMALES PARA LA FORMACIÓN DE MAESTROS}

Un importante cambio en la educación costarricense aconteció en las dos últimas décadas del siglo XIX, con la «Reforma a la Educación» de 1885. Esta puede sintetizarse a partir de cuatro acciones fundamentales: (1) la centralización de la educación, mediante la promulgación de la Ley Fundamental de Instrucción Pública y la Ley General de Educación Común; (2) la puesta en marcha de los cambios a la enseñanza primaria, que incluyen la división en grados, la concepción de una educación integral y la elaboración de un plan de estudios mínimos que debían abordarse; a esto se agrega la fundación de una Escuela Normal para varones, con una escuela de aplicación; (3) la reforma a la segunda enseñanza y la creación del Instituto de Alajuela y el Liceo de Costa Rica, con una Sección Normal para varones; y (4) la fundación del Colegio Superior de Señoritas, con una Sección Normal, y la planificación de una reforma a la educación superior. ${ }^{1}$

\footnotetext{
1 Bernal Martínez, Cronología de la educación costarricense (San José: Imprenta Nacional, 2016), 16; María Eugenia Dengo, Educación costarricense (San José: EUNED, 2011), 139-146; Juan Rafael Quesada, Un siglo de educación costarricense 1814-1914 (San José: Editorial de la Universidad de Costa
} 
La creación de colegios para la educación secundaria, producto de esta Reforma, tuvo un impacto sobresaliente en la formación de maestros. Los colegios para varones y para niñas promovieron la formación de maestros y maestras, respectivamente, en las conocidas Secciones Normales, que eran parte de estas instituciones, principalmente en zonas centrales del país.

En las Secciones Normales se impartía una capacitación adicional a aquellos estudiantes de secundaria que querían desempeñarse como maestros; esta capacitación incluía una serie de cursos adicionales —que incluían las matemáticas-, la presentación de conferencias y la aplicación de exámenes para maestros, complementados con las políticas de inspección vigentes y el asesoramiento necesario.

A pesar de los esfuerzos por una formación particularizada de maestros, esta "profesionalización» era incompleta e insuficiente, casi una falacia. Astrid Fishel destaca que «la formación y capacitación de docentes en las llamadas 'secciones normales' del Liceo de Costa Rica y del Colegio Superior de Señoritas, no lograron aliviar de manera significativa, las grandes necesidades de personal docente». ${ }^{2}$ La formación en las Secciones Normales solo incorporaba algunas nociones de pedagogía, temas adicionales al bachillerato de segunda enseñanza y al comercio.

Los cambios realizados producto de la Reforma Educativa lograban la «institucionalización del empirismo docente», ${ }^{3}$ pero no la especialización del maestro en tendencias de una carrera de magisterio. ${ }^{4}$

La preparación «teórica» de los futuros maestros se complementaba con una preparación práctica preliminar; "para lo relativo a "formación inicial" de los maestros, hubo "escuelas modelo" que funcionaban anexas

\footnotetext{
Rica, 2005) 12; Vladimir de la Cruz, "La educación y la cultura costarricense en el siglo XIX: de las Cortes de Cádiz a las Reformas educativas», en Historia de la Educación Costarricense, ed. Jorge Mario Salazar (San José: EUNED, 2003), 1-71; Elías Zeledón, Crónicas para la historia de la educación costarricense. Desde sus orígenes hasta la creación de la Universidad de Costa Rica (San José, EUNED, 2014), 9.

2 Astrid Fishel, "La educación costarricense: entre el liberalismo y el intervencionismo", Historia de la Educación Costarricense, ed. Jorge Mario Salazar (San José: EUNED, 2003), 83.

${ }^{3}$ Quesada, Un siglo de educación costarricense 1814-1914, 32.

${ }^{4}$ Zeledón, Crónicas para la historia de la educación costarricense, 92-93.
} 
tanto al Liceo de Costa Rica como al Colegio Superior de Señoritas»,5 para la práctica docente; algunas de estas estuvieron a cargo de maestros extranjeros, mientras los maestros costarricenses culminaban su preparación.

Para finales del siglo XIX e inicios del siglo XX, la forma incipiente, moderna y científica de concebir la pedagogía y de organizar la formación de maestros se había institucionalizado, derivando en un incremento de Secciones Normales en diversos centros educativos de segunda enseñanza en el país.

\section{La enseñanza de la aritmética en Costa Rica}

El estudio de la aritmética se reconoce en la enseñanza de la numeración en las escuelas de primeras letras (siglo XVIII). Estas escuelas eran centros para la cristianización y la transmisión del uso del castellano (la lengua) a los nativos, y para la transmisión del «conocimiento castellano» a los criollos, descendientes de los colonos.

Con la fundación de la Casa de Enseñanza de Santo Tomás, en 1814, se dio una modificación en la tutela religiosa, pero la escritura, la lectura y la doctrina cristiana continuaron siendo parte de las «primeras letras». La oferta educativa incorporó gramática y aritmética, incluso geometría. Este desarrollo es aún más evidente con la inclusión de la matemática como parte de los estudios «menores» en la Universidad de Santo Tomás y, luego, como área de estudio. Aritmética, álgebra —principalmente- y geometría, constituían las áreas de las matemáticas que un graduado de esta Universidad debía conocer. La aritmética se impartía en los primeros cursos de preparación.

Para destacar algunas particularidades conceptuales en cuanto al tratamiento de la aritmética, se han tomado como referencia tres libros de texto, editados en momentos distintos del siglo XIX. Primero, el texto Brebes lecciones de arismética, primer libro editado en el país en 1830 por el Bachiller Rafael Osejo. Luego, se destaca la propuesta de Carlos Francisco Salazar en su libro Curso de aritmética razonada, editado en

\footnotetext{
5 Dengo, Educación costarricense, 148.
} 
1885. ${ }^{6}$ Por último, se describe la obra de Félix Francisco Noriega, titulada Manual para el maestro. Curso elemental de aritmética, arreglado de acuerdo con los programas oficiales», editada en 1897.

\section{Las Brebes lecciones de arismética de Rafael Osejo (1830)}

Al igual que han reconocido Pedro Rodríguez y Ángel Ruíz, el texto de Osejo se estructura en cinco apartados temáticos. ${ }^{7}$ El primero, dedicado a los conceptos básicos sobre aritmética, expone los conceptos de cantidad, número y unidad; una tipificación del número como homogéneo, heterogéneo, simple o compuesto, entero, quebrado y fraccionario; se continúa con la presentación de «tres operaciones» con los números: expresión (numeración), composición y descomposición (cálculo). Se sigue con las denominadas «reglas fundamentales del cálculo aritmético»: sumar y restar, las «reglas secundarias del cálculo»: sumar, restar, multiplicar, dividir, elevar a potencias y extraer raíces, las definiciones y elementos de las reglas, teoremas sobre la multiplicación y la división y las reglas para la división.

El segundo apartado se vincula a los números quebrados, su definición y representación; teoremas; operaciones con quebrados; común denominador. La teoría de los decimales constituye el tercer apartado, destaca la definición y escritura de estos números y las operaciones con decimales. La enseñanza de la aritmética continúa con la presentación de potencias y raíces; se definen, se muestran la relación entre potencias y raíces, y se establecen procedimientos para aproximar el cálculo de la raíz cuadrada y cúbica.

Por último, se tratan las razones y proporciones; se define razón; se muestran tipos de razones: aritmética y geométrica; la definición de proporción, tipos de proporciones: aritmética y geométrica, la proporción discreta y proporción continua; la definición de progresión, la propiedad de las proporciones aritmética y geométrica; el apartado termina con la exposición de aplicaciones de las proporciones.

\footnotetext{
6 Carlos Francisco Salazar, Curso de aritmética razonada (San José: Imprenta Nacional, 1885).

7 Pedro Rodríguez y Ángel Ruíz, «Antes de la Reforma de Mauro Fernández», en Historia de las Matemática en Costa Rica, ed. Ángel Ruíz (San José: EUCR/EUNA, 1994), 22-34.
} 
Este texto «muestra lo que sería durante estos años la formación matemática de la época». ${ }^{8}$ Una exposición básica o elemental de la aritmética, para su enseñanza en primaria y los primeros años de secundaria.

\section{El Curso de aritmética razonada de Carlos Salazar (1885)}

El texto de Carlos Francisco Salazar presenta un esquema de la formación en aritmética que se impartía más de medio siglo después de la edición del texto de Osejo. ${ }^{9}$ Compuesto por 12 capítulos, se presentan desde nociones preliminares de las matemáticas y la aritmética, hasta las especificidades del Sistema Métrico Decimal, ya vigente en la época en Costa Rica.

El texto se inicia con la presentación de los sistemas de numeración: decimal, romano y otros. Las operaciones fundamentales: adición y sustracción, se aplican a cantidades positivas y negativas, junto a la presentación del complemento de un número. Un tercer apartado, titulado "Abreviaciones de las fundamentales», destaca la multiplicación, las reglas de signos, la división y sus teoremas, las potencias y la extracción de raíces. Esto se complementa con otra sección sobre las pruebas de las operaciones. La divisibilidad y los números primos constituyen otro tema de interés, se destaca su definición, el máximo común divisor, el mínimo común múltiplo y los números primos.

Los apartados siguientes acentúan las fracciones, las fracciones decimales, los números inconmensurables, las progresiones y los logaritmos, todos como secciones de una teoría matemática particular. La teoría general de las fracciones se destina a la presentación de definiciones, las fracciones ordinarias, el proceso de simplificación, igualdades; también, operaciones con fracciones: adición, sustracción, multiplicación, división, potencias y raíces. La teoría de las fracciones decimales muestra su tratamiento desde las operaciones adición, sustracción, multiplicación, potencias y raíces; la transformación de fracciones y las fracciones

\footnotetext{
8 Rodríguez y Ruíz, «Antes de la Reforma de Mauro Fernández», 26.

9 Rodríguez y Ruíz, «Antes de la Reforma de Mauro Fernández», 30; Ruth González-Arrieta y Xinia Moya-López, «Libros de la Universidad de Santo Tomás preservados en la Biblioteca Nacional», Bibliotecas 34 (2016): 59-93. DOI: http://dx.doi.org/10.15359/rb.34-2.3
} 
continuas. Le siguen las cantidades inconmensurables y las operaciones con estos números, y la progresión geométrica.

La teoría general de logaritmos incluye su definición, la construcción de tablas y los exponentes de Lagrange, el método de Long, el sistema de logaritmos y la presentación de tablas de logaritmos. En cuanto a los exponentes de Lagrange, el autor destaca un procedimiento para construir tablas logarítmicas sin recurrir a las progresiones. Este procedimiento se expone mediante un ejemplo en el que se calcula el logaritmo de 2 en base $10(\log 2)$ y se propone para calcular los logaritmos correspondientes a 3, 5 y $7 .{ }^{10} \mathrm{El}$ método de Long se propone como una estrategia para calcular logaritmos de números grandes; el autor destaca un ejemplo para el cálculo de logaritmos, sugiere la elaboración de una tabla de valores y describe la manera de utilizar la tabla. ${ }^{11}$

En la parte final del texto, se presenta la resolución de problemas en diversas situaciones vinculadas a las finanzas y otros contextos. También, se destaca el Sistema Métrico Decimal, enfatizando su definición, equivalencias, medidas inglesas y francesas, y las monedas. El texto termina con la presentación de reglas y arbitrajes en el apartado dedicado al tiempo y su medida.

Esta descripción del texto de Salazar muestra cambios notables en el abordaje de la aritmética. Destaca la exposición de cantidades negativas, los números primos, el estudio de los números inconmensurables, los logaritmos, el sistema métrico decimal y la medida del tiempo, estos últimos como temas propios de la época de adopción del sistema metrológico.

Félix Francisco Noriega y el Manual de aritmética para el maestro (1897)

Desde un marco general, este libro de texto fue editado en San José en 1897, por la Imprenta Comercial; formaba parte de la «Colección de Textos Nacionales» para la Enseñanza Primaria en Costa Rica. El texto se presenta como una versión mejorada del trabajo publicado previamente en el «Boletín de las Escuelas Primarias». Como indica su autor, el

\footnotetext{
10 Salazar, Curso de aritmética razonada, 186-187.

11 Salazar, Curso de aritmética razonada, 189-191.
} 
sustento conceptual y pedagógico del texto toma en cuenta diversas propuestas de autores extranjeros, como G. Ritt, F. Vintejoux y Garcés, y las ideas de A. Blume sobre la enseñanza de la aritmética.

Desde las expectativas para su elaboración, el texto respondió a un «desorden evidente en la enseñanza de la aritmética en las escuelas primarias», que su autor pudo constatar mientras se desempeñaba como inspector de educación en la provincia de Alajuela. Con base en esto, el autor justifica la elaboración del texto "por la falta de un programa bien meditado, y lo que más aún, por la de un texto que guiara al maestro en la enseñanza de las proposiciones fijadas en aquél». ${ }^{12}$

En cuanto a su estructura, el libro de texto corresponde a un único volumen de 195 páginas; su contenido se organiza a partir de cuatro secciones, correspondientes a los primeros cuatro años de educación primaria — de seis en total—.

La primera sección del texto (primer año) incluye la numeración, desde el abordaje de las nociones de cantidad, unidad y número; las representaciones de los números hasta diez —incluyendo una introducción a las operaciones suma y resta-, luego hasta 20 - con las operaciones suma y resta- y por último hasta 100 (con la suma, resta, multiplicación y división). Para el segundo año se continúa con la numeración hasta 1000 , las operaciones básicas con estos números, la introducción del metro para el estudio de unidades de medida de longitud y superficie. En el tercer año se dispone el estudio de los números fraccionarios y las operaciones, junto con las unidades de medida para el peso. Finalmente, en el cuarto año se completa el estudio del Sistema Métrico Decimal y se enfatizan las fracciones decimales, se presentan las medidas «antiguas» y el sistema monetario.

El apartado de hermenéutica expone las particularidades matemáticas (conceptuales y procedimentales) y didácticas reconocidas en este texto, a partir de la aplicación de categorías específicas del análisis didáctico como metodología de estudio de libros de texto históricos. ${ }^{13} \mathrm{Su}$

\footnotetext{
12 Felix Francisco Noriega, Manual para el maestro. Curso elemental de aritmética (San José: Imprenta Comercial, 1897), 5.

13 Miguel Picado y Luis Rico, «Análisis de contenido en textos históricos de matemáticas» PNA 6, no. 1 (2011): 11-27. http://hdl.handle.net/10481/16013
} 
selección como fuente de información histórica obedece a su representatividad en la formación de maestros en las Secciones Normales de la época, previas a la fundación de la Escuela Normal.

\section{ANTECEDENTES DEL ESTUDIO}

Particularizando a los estudios basados en el análisis de libros de texto como fuentes de información, este tipo de trabajos ha posibilitado el análisis de diversos fenómenos asociados a las especificidades conceptuales y procedimentales de las matemáticas escolares, a los planteamientos curriculares para su enseñanza y aprendizaje, a la formación matemática de docentes, entre otros aspectos, en épocas pasadas. ${ }^{14}$

El análisis de libros de texto, desde una perspectiva histórica, permite responder a cuestiones educativas no explicadas por la historiografía tradicional. ${ }^{15}$ Con los estudios históricos que analizan fuentes documentales, como libros de texto y documentos curriculares, es posible abordar «las reformas curriculares, los conceptos [matemáticos] y los modos de representación de estos conceptos, las situaciones y contextos utilizados en su presentación, así como las finalidades y tareas presentadas para su aplicación». ${ }^{16}$

\section{Estudios sobre la formación de maestros}

Como marco referencial, los procesos de formación de maestros han sido objeto de estudio en diversas investigaciones a nivel internacional.

Dolores Carrillo acentúa y delimita la formación de maestros en España desde la denominada "Metodología de la aritmética», como un componente de las asignaturas pedagógicas para su formación — de los

\footnotetext{
${ }^{14}$ Kristín Bjarnadóttir et al., «Dig Where you Stand» 4. Proceedings of the Fourth International Conference on the History of Mathematics Education (Roma: Edizioni Nuova Cultura, 2017).

15 Gert Schubring, «Categorías teóricas para la investigación en la historia social de la enseñanza de la matemática y algunos modelos característicos», Épsilon 19 (1991): 100-104. https://thales.cica.es/ epsilon/?q=content/epsilon-n\%C2\%BA-77-a\%C3\%B1o-2011-volumen-28-1

16 Miguel Picado, «El Sistema Métrico Decimal en libros de texto de matemáticas en España durante la segunda mitad del siglo XIX (1849-1892)» (Tesis doctoral, Universidad de Granada, 2012), 116.
} 
maestros- en las Escuelas Normales durante el segundo tercio del siglo XIX. ${ }^{17}$ Carmen López detalla las particularidades de la enseñanza de la aritmética y el álgebra, mostradas en algunos manuales escolares, y enmarca su investigación en lo que denomina: el «saber escolar» de la formación de maestros. ${ }^{18}$ Miguel Picado analiza una serie de libros de texto para el estudio de los cambios curriculares ocurridos en la formación de maestros con la incorporación del Sistema Métrico Decimal en el Sistema Educativo español durante la segunda mitad del siglo XIX. ${ }^{19}$

En el caso de Costa Rica, Ana Agüero, Marta Baires, Marycruz Murillo y Lourdes Ulate enfatizan sobre las experiencias educativas que tuvieron los formadores de maestros desde la descripción de su práctica docente en los últimos años de la Escuela Normal. ${ }^{20}$ Otros trabajos se dirigen a destacar elementos generales vinculados con la creación de este centro de formación y algunos hacen el intento por profundizar en elementos administrativos y pedagógicos..$^{21}$

Estos trabajos acentúan la génesis, la creación y el legado de la Escuela Normal de Costa Rica, se aproximan a los fundamentos pedagógicos que caracterizaron la formación de maestros durante su existencia. Sin embargo, queda sin abordar el estudio de documentos curriculares, como programas y libros de texto propuestos para la formación de maestros, que caracterizan desde las matemáticas y la didáctica, la enseñanza y el aprendizaje de los docentes normalistas en esta disciplina.

\footnotetext{
${ }_{17}$ Dolores Carrillo, La metodología de la aritmética en los comienzos de las Escuelas Normales (18381868) y sus antecedentes (Murcia: Universidad de Murcia, 2005).

${ }^{18}$ Carmen López, «La formación inicial de maestros en aritmética y álgebra a través de los libros de texto» (Tesis doctoral, Universidad de Salamanca, 2011).

19 Picado, «El Sistema Métrico Decimal en libros de texto de matemáticas en España durante la segunda mitad del siglo XIX (1849-1892)».

20 Ana Agüero et al., «Experiencias educativas de los formadores de docentes en la Escuela Normal de Costa Rica (1951-1973). "Lecciones del pasado"» (Tesis de Licenciatura, Universidad Nacional, 2008).

${ }_{21}$ Carlos Montero, «La Escuela Normal de Costa Rica», 14 de agosto de 2010. https://carlosmontero. blogia.com/; Iván Molina Jiménez, «Centenario de la apertura de la Escuela Normal». La Nación (Costa Rica), 1 de marzo de 2015; Andrea Solano, «La cuna de los educadores ticos festeja su centenario», La Nación (Costa Rica), 30 de noviembre de 2014.
} 


\section{POSICIONAMIENTO TEÓRICO DEL ESTUDIO}

Teóricamente, el estudio se fundamenta en las investigaciones en historia de la Educación Matemática basadas en el análisis de textos históricos.

La investigación histórica se ha abordado desde distintos campos de estudio, reconocibles en diversos trabajos de investigación. Miguel Picado plantea tres focos temáticos sobre los cuales se ha mirado la investigación histórica. Primero, puntualiza el abordaje de esta investigación desde «aspectos teóricos de la historia como disciplina, como el objeto de su estudio, su finalidad y las diversas ideas sobre la objetividad del conocimiento histórico"; 22 aquí se muestra un acercamiento entre historia y ciencia. ${ }^{23}$

Otro de estos focos atiende sobre cuestiones propias de su metodología, acentuando el método histórico o el método historiográfico. ${ }^{24} \mathrm{En}$ este, los estudios «caracterizan una investigación histórica a partir de la presentación de una serie de pasos que desarrollan y organizan sistemáticamente».25

Finalmente, se reconocen trabajos orientados a la presentación de una metodología para la investigación histórica, pero que además plantean una concepción de la investigación histórica; es decir, proponen ideas diversas sobre el significado de la investigación histórica como actividad en el campo de las ciencias. ${ }^{26}$ Desde este foco es posible resaltar algunas de las concepciones sobre la investigación histórica.

\footnotetext{
22 Picado, «El Sistema Métrico Decimal en libros de texto de matemáticas en España durante la segunda mitad del siglo XIX (1849-1892)», 123-124.

${ }^{23}$ Federico Suárez, La historia y el método de investigación histórica (Madrid: Rialp, 1977); John Losee, Filosofía de la ciencia e investigación histórica (Madrid: Alianza, 1989); Jacques Le Goff, Pensar la Historia. Modernidad, presente, progreso (Barcelona: Paidós, 2011).
}

${ }^{24}$ Neil J. Salkind, Métodos de investigación (Ciudad de México: Prentice-Hall, 1999); Ciro F. S. Cardoso, Introducción al trabajo de la investigación histórica: conocimiento, método e historia (Barcelona: Crítica, 2000); Julio Aróstegui, La investigación histórica: teoría y método (Barcelona: Crítica, 2001); Louis Cohen y Lawrence Manion, Métodos de Investigación Educativa, 2a ed. (Madrid: La Muralla, 2002).

${ }_{25}$ Picado, «El Sistema Métrico Decimal en libros de texto de matemáticas en España durante la segunda mitad del siglo XIX (1849-1892)», 124.

${ }^{26}$ David Fox, El proceso de investigación en educación (Pamplona: Universidad de Navarra, 1987); Losee, Filosofía de la ciencia e investigación histórica; Suárez, La historia y el método de investigación histórica. 
Este trabajo se posiciona dentro del marco de aquellas investigaciones que destacan una metodología de análisis de fuentes primarias de información - libros de texto- para el estudio de acontecimientos históricos, particularmente en Educación Matemática. ${ }^{27}$

Gerl Schubring destaca que el análisis histórico de libros de texto requiere del estudio de distintas ediciones de un texto y las incidencias de estos cambios en otros textos, y su relación con los avances o reformas en los planes de formación, la evolución de las matemáticas, las discusiones sobre la enseñanza, entre otros. ${ }^{28}$

En este caso, el foco de atención lo constituye el abordaje de la aritmética en los procesos de formación de maestros en Costa Rica. Para esto, se han tomado en cuenta tres libros de texto editados en el siglo XIX (en los años 1830, 1885 y 1893), para describir la enseñanza de la aritmética en educación primaria y en los centros de formación de maestros en la época. Particularmente, el análisis llevado a cabo tomó como referente el texto editado a finales de siglo, cuando ya estaban establecidas las Secciones Normales del Liceo de Costa Rica y el Colegio Superior de Señoritas, fundados en 1886 y 1888, respectivamente.

\section{UNA CONCEPTUALIZACIÓN DE LA INVESTIGACIÓN HISTÓRICA EN EDUCACIÓN MATEMÁTICA}

A través de una integración de concepciones, Miguel Picado se refiere a la investigación histórica y su propósito como sigue:

la investigación histórica exige, y a la vez permite, reflexionar sobre la historia misma, sobre las características del método histórico y las cualidades de un investigador histórico, conduce a una reflexión sobre el conocimiento, la epistemología y la teoría. Investigar en historia no es contar una serie de datos cronológicamente expuestos. Es indagar, describir y analizar datos; es ilustrar contextos y

\footnotetext{
${ }^{27}$ Alexander Maz, «Los números negativos en España en los siglos XVIII y XIX» (Tesis doctoral, Universidad de Granada, 2005); Picado, «El Sistema Métrico Decimal en libros de texto de matemáticas en España durante la segunda mitad del siglo XIX (1849-1892)».

${ }_{28}$ Gert Schubring, "On the Methodology of Analysing Historical Textbooks: Lacroix as textbook author». For the Learning of Mathematics 7, no. 3 (1987): 41-51. https://flm-journal.org/index.php?$\mathrm{do}=$ show\&lang $=$ en $\&$ show $\mathrm{Menu}=7 \% 2 \mathrm{C} 3$
} 
situaciones; es integrar, interpretar y evaluar. La investigación histórica permite compartir el conocimiento de la realidad histórica, en la búsqueda de explicaciones y respuestas para las diversas circunstancias y problemas de la convivencia entre los hombres. ${ }^{29}$

Desde esta perspectiva conceptual, y de las particularidades de la educación matemática, se adopta la investigación histórica en educación matemática como el medio para conocer sobre los orígenes de un sistema educativo, el desarrollo de teorías y prácticas educativas, y para profundizar en las particularidades de los fenómenos asociados a la enseñanza y el aprendizaje de las matemáticas. La investigación histórica se entiende como una acción útil para aclarar cuestiones de la didáctica de la matemática que son de interés actual, a través del estudio de materiales existentes. Su mayor diferencia de otros tipos de investigación lo constituyen estos materiales que son sus fuentes de información, como libros de texto o documentos curriculares oficiales.

En este estudio, se pretende profundizar en los orígenes de la formación matemática de maestros y las prácticas educativas para la Educación Primaria; esto mediante el estudio de textos históricos para la enseñanza y el aprendizaje de las matemáticas, editados en Costa Rica durante el siglo XIX.

\section{METODOLOGÍA}

El estudio se enmarca en las investigaciones cualitativas descriptivas, basadas en el análisis de libros de texto. ${ }^{30}$ Está orientado por la metodología de la investigación histórica a través de las fases propuestas por Miguel Picado y Luis Rico; estas son: (1) planteamiento de la investigación; (2) selección de las fuentes; (3) análisis de las fuentes seleccionadas; (4) interpretación de los datos, y (5) comunicación de los

\footnotetext{
29 Picado, «El Sistema Métrico Decimal en libros de texto de matemáticas en España durante la segunda mitad del siglo XIX (1849-1892)», 125.

30 María Teresa González, «Sistemas simbólicos de representación en la enseñanza del análisis matemático: perspectiva histórica acerca de los puntos críticos» (Tesis doctoral, Universidad de Salamanca, 2002); Carrillo, La metodología de la aritmética en los comienzos de las Escuelas Normales (1838-1868) y sus antecedentes; Maz, «Los números negativos en España en los siglos XVIII y XIX»; Carmen López, «La formación inicial de maestros en aritmética y álgebra a través de los libros de texto» (Tesis doctoral, Universidad de Salamanca, 2011).
} 
resultados. ${ }^{31}$ En lo que sigue se enfocan tres de estas fases: el proceso de selección de la fuente y su descripción, el análisis y la interpretación de la información.

\section{Selección del libro de texto}

Para este estudio se ha tomado como fuente primaria un libro de texto publicado como un manual, destinado al maestro, para la enseñanza de la aritmética en educación primaria.

Se entiende por fuente primaria a «aquellos sujetos o artículos originales con una relación directa, en tiempo y espacio, con el hecho en estudio» ${ }^{32}$ Estas fuentes de información son textos que muestran las disposiciones curriculares para la formación de maestros en las Secciones Normales del siglo XIX y para la enseñanza de la aritmética a los escolares de la educación primaria en la misma época.

La selección del libro de texto tomó en cuenta una serie de criterios adoptados de estudios preliminares. ${ }^{33}$ Estos son: (a) fecha y lugar de publicación, que asegura que la edición del texto se haya dado durante la vigencia de las Secciones Normales en el siglo XIX y que correspondiera a un documento editado en Costa Rica; (b) título con la denominación Aritmética, para destacar el vínculo del texto con la enseñanza de esta asignatura; (c) la enseñanza como finalidad, que acentúa su uso en la educación matemática; (d) disponibilidad del texto, para asegurar el acceso al contenido del documento en cualquier momento; y (e) originalidad, para tener certeza de contar con una fuente primaria de información.

La localización y ubicación del documento se realizó a través de una visita a la Biblioteca Nacional de Costa Rica y de su búsqueda en el

\footnotetext{
${ }_{31}$ Miguel Picado y Luis Rico, «La selección de textos en una investigación histórica en educación matemática», Épsilon 77, no. 1 (2011): 99-112. https://thales.cica.es/epsilon/sites/thales.cica.es.epsilon/files/epsilon77.pdf

32 Picado y Rico, «La selección de textos en una investigación histórica en educación matemática», 103.

${ }^{33}$ Picado y Rico, «La selección de textos en una investigación histórica en educación matemática», 99-112.
} 
portal electrónico de este centro de documentación, donde fue posible tener acceso a una versión digital del documento. ${ }^{34}$

Aunado a esto, se destaca la crítica histórica que permite evaluar la autenticidad y exactitud de la fuente. Siguiendo a John W. Best, Neil J. Salkind, Louis Cohen y Lawrence Manion es necesario comprobar, a través de un proceso de crítica externa, la autenticidad del documento y la legitimidad de los datos, ${ }^{35}$ es decir «descubrir fraudes, falsificaciones, engaños, invenciones o distorsiones». ${ }^{36}$ Asimismo, con la crítica interna, se requiere de una valoración de la exactitud del contenido del texto. Para este estudio, se comprobó la originalidad de la fuente mediante la visita a la Biblioteca Nacional de Costa Rica y se verificó la veracidad de los datos a través de la revisión de su contenido. Con esto se ha asegurado la aceptación de los datos como evidencia histórica para el estudio.

\section{Caracterización del autor}

Félix Francisco Noriega, nació en Colombia. Siguiendo a Luis Felipe González y Guillermo Malavassi y Pedro Gutiérrez,, ${ }^{37}$ Noriega formó parte de un grupo de profesionales y ciudadanos de la República de Colombia que inmigraron a Costa Rica, a causa de la diferencia de opiniones sobre la situación política de esa nación.

F. F. Noriega - como se indica en el libro de texto- fue profesor de pedagogía en las Escuelas Normales de Santander en Colombia y fungió como rector del Colegio de La Asunción en Venezuela.

Después de su llegada a Costa Rica, en 1890, se desempeñó como inspector de escuelas en la Provincia de Alajuela, tuvo a su cargo la dirección del Instituto de Alajuela y la jefatura de la Sección Administrativa de

\footnotetext{
${ }^{34}$ Enlace para el sitio web de la Biblioteca: http://sinabi.go.cr/ver/biblioteca\%20digital/libros\%20 completos/noriega $\% 20$ felix $\% 20$ francisco/curso $\% 20$ elemental $\% 20 \mathrm{de} \% 20$ aritmetica.pdf\#.W-S1m5NKiUl

35 John W. Best, ¿Cómo investigar en educación? (Madrid: Morata, 1982); Salkind, Métodos de investigación; Cohen y Manion, Métodos de Investigación Educativa.

${ }^{36}$ Cohen y Manion, Métodos de Investigación Educativa, 87.

${ }^{37}$ Luis Felipe González, Historia de la influencia extranjera en el desenvolvimiento educacional y científico de Costa Rica (San José: Imprenta Nacional, 1921), 109; Guillermo Malavassi y Pedro Gutiérrez, Diccionario biográfico de Costa Rica (San José: Universidad Autónoma de Centro América, 1992), 163.
} 
Enseñanza, esto último le permitió impartir distintas cátedras en colegios de segunda enseñanza.

Su producción bibliográfica incluye obras propias del contexto costarricense, como el Diccionario Geográfico de Costa Rica y la publicación de artículos vinculados a la educación en el Boletín de las Escuelas; de estas últimas contribuciones, y de su experiencia como inspector de escuelas, se desprende el texto de aritmética que ha sido fuente de información para este estudio.

El desempeño de F. F. Noriega en la educación costarricense, desde su vínculo con la administración pública, la docencia y la producción bibliográfica, es una prueba de la influencia extranjera en el desarrollo de la educación matemática en Costa Rica.

\section{Análisis de la información}

El análisis del contenido del libro de texto se ha llevado a cabo mediante las categorías propuestas por Miguel Picado y Luis Rico, ${ }^{38}$ y la adaptación de las categorías del análisis didáctico sobre lo cognitivo, de instrucción y de evaluación, ${ }^{39}$ para el estudio de libros de texto históricos de matemáticas. Estas categorías responden a un primer nivel de análisis; es decir, se consideran categorías generales. Un segundo nivel de análisis incluye categorías secundarias —asociadas a las generalesy unidades de análisis, estas últimas definidas a partir del contenido del libro de texto analizado. En este caso se resaltan los conceptos y procedimientos aritméticos asociados a las sugerencias didácticas, identificadas en el texto, para su enseñanza.

Se entienden las sugerencias didácticas como aquellas indicaciones puntuales, que realiza el autor del libro de texto, con tres propósitos: (a) resaltar particularidades cognitivas del estudiantado, (b) proponer formas específicas de enseñanza para determinados conceptos y procedimientos matemáticos, y (c) referir a proposiciones de evaluación

\footnotetext{
38 Picado y Rico, "Análisis de contenido en textos históricos de matemáticas», 11-27.

39 Luis Rico y Antonio Fernández-Cano, "Análisis didáctico y metodología de investigación», Análisis Didáctico en Educación Matemática. Metodología de investigación, formación de profesores e innovación curricular, eds. Luis Rico, José Luis Lupiáñez y Marta Molina (Granada: Comares, 2013), $1-22$.
} 
particulares. Estas son las categorías consideradas generales para el análisis de la información del libro de texto.

\section{HERMENÉUTICA}

A continuación, se muestran algunas indicaciones identificadas en el texto seleccionado, y los conceptos aritméticos asociados a estas, para le enseñanza de la aritmética. Los resultados del análisis se presentan a partir de las tres categorías generales definidas para el estudio, las categorías secundarias y las unidades de análisis definidas.

\section{Sobre las particularidades cognitivas del estudiantado}

Las sugerencias didácticas en esta categoría se refieren a indicaciones propuestas por el autor para promover el aprendizaje del estudiantado. Con especificidad, destacan las sugerencias sobre el logro de aprendizajes particulares, la presencia de dificultades y posibles errores intrínsecos a los conceptos matemáticos, y las tareas que se proponen para incentivar ese aprendizaje.

\section{Logro de aprendizajes particulares}

Para este aspecto, se han reconocido cuatro tipos de sugerencias que el autor del libro de texto le indica al maestro, que se detallan a continuación.

Repetición de información o acciones: se sugiere que el estudiantado repita en coro la definición de conceptos, las respuestas a las preguntas o las afirmaciones hechas por el maestro, y que realice distintos movimientos de manera coordinada, como trazos en el aire, para la memorización de información. Por ejemplo, se sugiere la repetición de respuestas, por parte del estudiantado, como una estrategia para el aprendizaje del concepto de unidad:

- Qué tengo en la mano?

- En la mano tiene un libro.

Hágase que todos repitan en coro la respuesta anterior, lo cual se hará con las demás que vayan dando los niños que se interroguen particularmente. 
- Cuántos lápices tengo en la mano?

- En la mano tiene un lápiz.

- Cuántas mesas hay en la escuela?40

Uso de cálculo mental: se sugiere la realización de operaciones mediante el cálculo mental sin el uso de materiales o recursos. Se destaca el uso del cálculo mental en la resolución de tareas vinculadas a la adición de números del 10 al 20.

Finalmente, serán resueltas mentalmente las cuestiones que siguen, y otras semejantes:

$1^{\mathrm{a}}$. - Cuántos días componen dos semanas? Se exigirá que el niño explique cómo halla el resultado. En el caso presente él dirá que 14 son los días que componen las 2 semanas, porque $7+7$ son $14 .{ }^{41}$

Reconocimiento de capacidades o habilidades: se sugiere tomar en cuenta las capacidades o habilidades del estudiantado de manera preliminar a la presentación y asignación de tareas. Por ejemplo, los siguientes párrafos muestran dos indicaciones del autor sobre aspectos que el maestro debe considerar para el aprendizaje del concepto de división.

Para averiguar, por ejemplo, cuánto suman 7 más 5, el maestro separará primero 7 bolas á las cuales agregará luego 3, á fin de cubrir el número 10. Por los ejercicios de la lección (7), los niños saben que si de cinco bolas se quitan tres bolas, quedan dos bolas. ${ }^{42}$

Esta cuestión: $24 \div 4=$ ? se puede leer de dos modos: $1^{\circ}$. Cuántas veces el número 4 está contenido en el 24 ?; $2^{\circ}$. Cuál es la $4^{\text {a }}$. parte de 24? Al principio debe preferirse el segundo, que es el más comprensible para los niños. ${ }^{43}$

\footnotetext{
${ }^{40}$ Noriega, Manual para el maestro. Curso elemental de aritmética, 9.

${ }^{41}$ Noriega, Manual para el maestro. Curso elemental de aritmética, 44.

${ }_{42}$ Noriega, Manual para el maestro. Curso elemental de aritmética, 41.

${ }_{43}$ Noriega, Manual para el maestro. Curso elemental de aritmética, 81.
} 
El primero destaca el enlace que el autor realiza con los conocimientos abordados en las lecciones anteriores y que, se supone, son del dominio del estudiantado. El segundo refiere al desarrollo cognitivo del estudiantado, en este caso su capacidad de comprensión.

Argumentación de respuestas: se sugiere que el maestro solicite al estudiantado que justifique, explique o amplíe sus respuestas a determinadas tareas o preguntas. Como ejemplo de esta indicación, en el caso de la división se sugiere que el estudiantado explique la obtención del cociente.

A fin de que los niños se posean bien de la naturaleza de la división, el maestro les explicará y hará que ellos expliquen, el sentido que envuelven razonamientos como éste: la $3^{\mathrm{a}}$. parte de 12 es 4, lo que se consigue sirviéndose de números concretos. Ejemplo: —si se reparten 12 naranjas entre 3 niños, cada uno recibirá cuatro naranjas. ${ }^{44}$

\section{Dificultades y posibles errores en el aprendizaje}

En cuanto a las dificultades y los errores sobre el aprendizaje del estudiantado se ha reconocido en el libro de texto una indicación para el maestro.

Especificidad de las tareas: se sugiere el uso de tareas particulares para afrontar dificultades ya reconocidas en el estudiantado durante el aprendizaje. Por ejemplo, se destaca la dificultad del estudiantado en el conteo, ascendente y descendente, y la asignación de tareas determinadas para su tratamiento. «Como á los niños se les dificulta pasar de una decena á otra, los siguientes ejercicios los adiestrarán: $1^{\circ}$.- Qué número sigue al 29 , al 49, al 69? etc. $2^{\circ}$.- Qué número hay antes del 30, del 70? etc.».45

\section{Tareas propuestas para el aprendizaje}

Las tareas propuestas para incentivar el aprendizaje en el estudiantado constituyen el componente principal del libro de texto. Las indicaciones del autor sobre su presentación se han clasificado en tres tipos.

\footnotetext{
${ }_{44}$ Noriega, Manual para el maestro. Curso elemental de aritmética, 56.

${ }_{45}$ Noriega, Manual para el maestro. Curso elemental de aritmética, 49.
} 
Cantidad de tareas: se sugiere al maestro presentar al estudiantado una cantidad moderada de tareas de manera que se evite el aburrimiento y el desinterés por su resolución. «Los niños copiarán estas operaciones y anotarán los resultados; pero no deben imponérseles tareas muy largas: una serie de las cinco que contiene la tabla, es bastante para un ejercicio. Después, se propondrá la adición de números tomados al acaso».46

Tareas orales: se recomienda la exposición de tareas orales que promuevan el aprendizaje del estudiantado. Por ejemplo, «4 $4^{\circ}$. - Una vez comprendido lo anterior, se procederá á resolver oralmente problemas en que el divisor sea un número dígito y el cociente uno de dos cifras»..$^{47}$

Tareas contextualizadas: se sugiere la inclusión de tareas en situaciones diversas que destaquen la utilidad de conceptos y procedimientos aritméticos, cuando estos se vinculan a fenómenos cotidianos para el estudiantado. Esta contextualización de tareas se evidencia en las tareas propuestas durante la enseñanza y en las listas de ejercicios que complementan el desarrollo de los temas (al final de los apartados en el texto o las lecciones).

El maestro escribe en el tablero estas tareas, sin indicar los resultados, los cuales deben ser hallados por los alumnos. Los siguientes problemas completarán esta lección:

$1^{\circ}$. - Tengo dos hermanas y á cada una le regalé tres rosas, cuántas rosas distribuí?

$2^{\circ}$. - Juan tiene dos pesetas y Pedro cinco; cuántas pesetas tienen ambos?

$3^{\circ}$. - Juan tiene dos hijos, $[\ldots] .48$

En cuanto a estas sugerencias didácticas sobre aspectos cognitivos del estudiantado, la tabla 1 muestra su relación con los conceptos matemáticos presentes en el libro de texto.

\footnotetext{
46 Noriega, Manual para el maestro. Curso elemental de aritmética, 42.

${ }_{47}$ Noriega, Manual para el maestro. Curso elemental de aritmética, 82.

${ }_{48}$ Noriega, Manual para el maestro. Curso elemental de aritmética, 28.
} 
Tabla 1. Conceptos asociados a sugerencias sobre las particularidades cognitivas del estudiantado

\begin{tabular}{|l|l|}
\hline \multicolumn{1}{|c|}{ Indicación } & \multicolumn{1}{c|}{ Conceptos } \\
\hline \multicolumn{2}{|c|}{ Logros de aprendizajes particulares } \\
\hline $\begin{array}{l}\text { Repetición de información o } \\
\text { acciones }\end{array}$ & $\begin{array}{l}\text { Unidad, cantidad, número, resta, metro, } \\
\text { múltiplos del metro. Superficie, fracciones } \\
\text { decimales, medidas agrarias, medidas cúbicas } \\
\text { (cubo), medidas de capacidad (líquidos), } \\
\text { decena, suma, valor posicional (u-d-c-...) }\end{array}$ \\
\hline Uso de cálculo mental & Suma, división \\
\hline $\begin{array}{l}\text { Reconocimiento de capacidades o } \\
\text { habilidades }\end{array}$ & Suma, división \\
\hline Argumentación de respuestas & Suma, división, multiplicación \\
\hline \multicolumn{2}{|c|}{ Dificultades y posibles errores en el aprendizaje } \\
\hline Especificidad de las tareas & Decena, antecesor, sucesor, estar entre \\
\hline \multicolumn{2}{|c|}{ Tareas propuestas para el aprendizaje } \\
\hline Cantidad de tareas & Suma \\
\hline Tareas orales & $\begin{array}{l}\text { Unidad, cantidad, número, suma, resta, decena, } \\
\text { división, antecesor, sucesor, estar entre, } \\
\text { multiplicación }\end{array}$ \\
\hline & $\begin{array}{l}\text { Suma y resta con números métricos, metro } \\
\text { cuadrado (múltiplos), división, multiplicación, } \\
\text { suma, resta, combinación de operaciones, } \\
\text { quebrado impropio }\end{array}$ \\
\hline
\end{tabular}

En cuanto a las expectativas de aprendizaje, de la tabla 1 se destaca el vínculo de las sugerencias identificadas con el tratamiento de las operaciones aritméticas, especialmente cuando se presentan la suma y la división. En particular, sobresale la cantidad de conceptos asociados a la repetición de acciones, orales o de escritura, que fomentan el aprendizaje memorístico en una primera etapa de aprendizaje. En etapas posteriores las sugerencias pretenden incentivar en el estudiantado la comprensión de significados de conceptos matemáticos mediante el cálculo mental y la justificación de respuestas por parte de este. 
El autor reconoce la dificultad del estudiantado para pasar de una decena a otra; para esto sugiere la asignación de tareas específicas basadas en el antecesor y sucesor de un número - conceptos implícitos en el texto-, que afronten esta dificultad y promuevan el aprendizaje. Más allá de esto, en el texto no se reconocen otras sugerencias que refieran a dificultades o posibles errores del estudiantado.

Por último, en cuanto a la presentación de tareas sobresale la contextualización, esto por la cantidad de conceptos que se asocian a esta sugerencia, destacando un trato reiterado para la suma, resta, multiplicación y división.

\section{Sobre las formas o modos de enseñanza sugeridos}

Aquí se consideran las indicaciones que hace el autor para que el maestro enseñe los conceptos y procedimientos aritméticos, mostrados en el libro de texto. Estas incluyen el uso de recursos y materiales, y la presentación de estrategias específicas para la exposición del contenido.

\section{Recursos y materiales}

Uso de materiales: se sugiere que el maestro utilice materiales diversos, como carteles de cartón u otro material, para la presentación de los diversos temas. Estos, en particular, son elaborados por el maestro, antes o durante la lección.

La siguiente tabla servirá para adiestrar á los niños en la descomposición de los números. Tanto ella como las demás que se inserten, deberán ponerse en una tabla ó cartón de 70 centímetros de longitud por 50 de latitud. Los puntos se figurarán en los cuadros grandes con puntos negros del tamaño de un cinco ó menos. ${ }^{49}$

El párrafo anterior muestra la indicación que hace el autor sobre la construcción de un cartel para el abordaje de la descomposición numérica.

${ }^{49}$ Noriega, Manual para el maestro. Curso elemental de aritmética, 20. 
También se acentúa el uso de materiales didácticos como el ábaco en la resolución de tareas: «por medio del ábaco los niños resolverán otras cuestiones semejantes». ${ }^{50}$

Uso de recursos: se sugiere la utilización de las «pizarras», el «tablero» y otros objetos concretos durante la enseñanza de conceptos o procedimientos. Las pizarras para el estudiantado se conciben como pequeños tableros donde este realiza apuntes; el tablero corresponde a un recurso que utiliza principalmente el maestro para mostrar información a todo el grupo.

Por ejemplo, el autor recomienda la implementación del tablero para la exposición de los múltiplos del metro. Así mismo, el uso de las pizarras para la adquisición de determinadas destrezas por parte del estudiantado, cuando resuelve tareas específicas:

Si á cada una de dichas palabras agregamos la palabra metro, resultarán estas otras que voy á escribir en el tablero y que son los nombres de otras tantas medidas. Decámetro que significa 10 metros. Hectómetro [que significa] 100 [metros], Kilómetro [que significa] 1,000 [metros], Miriámetro [que significa] 10,000 [metros]. ${ }^{51}$

Algunos de los objetos concretos considerados por el autor son libros, mesas, lápices, frutas, globos, entre otros. Mediante su uso se da una representación a determinados conceptos aritméticos. «-Cuántos lápices tengo en la mano? —En la mano tiene un lápiz. —Cuántas mesas hay en la escuela? —Una mesa. -Nómbrenme las cosas que hay en la escuela una vez».52

\section{Estrategias para la exposición del contenido}

Las sugerencias vinculadas a la exposición de los temas se reconocen a partir de la organización de las lecciones y las formas de mostrar los conceptos y procedimientos.

Planificación temática: se propone la enseñanza de un tema en lecciones distintas, a partir de las particularidades conceptuales o procedimentales. Por ejemplo, se sugiere una separación temática para el abordaje de la

\footnotetext{
${ }^{50}$ Noriega, Manual para el maestro. Curso elemental de aritmética, 53.

${ }_{51}$ Noriega, Manual para el maestro. Curso elemental de aritmética, 112.

${ }_{52}$ Noriega, Manual para el maestro. Curso elemental de aritmética, 9-10.
} 
escritura de los números de 0 a 9: «La enseñanza de los números que forman las dos familias que restan, dará tema para tres lecciones por lo menos, de modo que no deben enseñarse en cada lección, más de dos números».53

Reseña de contenidos: se sugiere que, al inicio de la lección, el maestro presente nuevamente algunos de los contenidos abordados en lecciones previas. Por ejemplo, «Al empezar cada lección, el maestro hará una recapitulación de la anterior, ó por lo menos una reseña de los puntos más salientes, para tomar de ella el desarrollo de la siguiente».54

Secuenciación de tareas: el autor recomienda la exposición de tareas a partir de criterios particulares que establecen un orden para su presentación. Estas secuencias destacan: (a) presentación de tareas orales de manera previa a las escritas; (b) presentación de tareas que involucren «números abstractos» antes de aquellas que incluyan «números concretos», es decir tareas que muestran una cantidad específica de objetos concretos; (c) exposición de tareas contextualizadas antes de la presentación de definiciones; (d) resolución de tareas manteniendo el orden de presentación en una lista dada, seguida de la asignación aleatoria de estas. A continuación se presentan indicaciones para los tipos (b) y (c) de secuenciación.

Se pasará ahora á resolver oralmente problemas referentes á los números de 20 á 100. Ejemplo:

— Cuál es la mitad de 54?

Resolución: $54=40+14$; la mitad de 40 es 20, y la de 14, 7; 20 $+7=27$; luego, la mitad de 54 es 27 . En seguida casos prácticos:

La mitad de 20 pesos, cuánto es?

Cuántos minutos tiene media hora?

Cuántas semanas son medio año?[...] $]^{55}$

Se pondrán en primer lugar algunas tareas prácticas con dos, tres ó más sumandos de tres cifras y luégo cuatro para entrar en las definiciones siguientes:

\footnotetext{
${ }_{53}$ Noriega, Manual para el maestro. Curso elemental de aritmética, 17.

${ }_{54}$ Noriega, Manual para el maestro. Curso elemental de aritmética, 12.

55 Noriega, Manual para el maestro. Curso elemental de aritmética, 84.
} 
Suma ó adición es una operación por medio de la cual se reúnen en uno solo, las unidades que contienen dos ó más números.

Las cantidades que se dan para sumar se llaman sumandos y el resultado total ó suma. ${ }^{56}$

Procedimientos invariables: se sugiere el establecimiento de procedimientos permanentes para la resolución de las operaciones. Por ejemplo, para la suma de números entre 100 y 1000 se sugiere el uso de un procedimiento específico que se considera invariable: sumar unidades con unidades, decenas con decenas y centenas con centenas: «El maestro habrá establecido previamente cierto modo de resolverlos, el cual una vez fijado no debe variarse». 57

Adaptación de estrategias expuestas: se sugiere el uso de instrucciones presentadas en lecciones previas, para el abordaje de temas particulares, adaptadas a la exposición de nuevos conceptos o procedimientos. Estas instrucciones incluyen la utilización del cuestionario y algoritmos para la resolución de operaciones. Por ejemplo, el uso del algoritmo para la resta de números enteros y su adaptación a la resta de las fracciones decimales: «esta operación [la resta de fracciones decimales] se practica lo mismo que la de los enteros, cuidando siempre de que la coma forme la vertical». ${ }^{58}$

Relaciones entre conceptos o procedimientos: se sugiere complementar la exposición o explicación de un tema destacando el vínculo de este con otros conceptos o procedimientos ya abordados. Como un caso particular se destaca un vínculo entre las operaciones multiplicación y suma: «Aquí se hará notar que la multiplicación es una adición abreviada, pues que lo mismo es multiplicar 6 por 8 , que escribir 8 veces el 6 y sumar; el resultado siempre es $48 » .59$

Casos particulares para la resolución de una operación: se sugiere abordar la presentación de las operaciones a partir de las particularidades de los números involucrados en estas. Por ejemplo, en el tema de fracciones

\footnotetext{
56 Noriega, Manual para el maestro. Curso elemental de aritmética, 104-105.

${ }^{57}$ Noriega, Manual para el maestro. Curso elemental de aritmética, 65.

58 Noriega, Manual para el maestro. Curso elemental de aritmética, 169.

59 Noriega, Manual para el maestro. Curso elemental de aritmética, 76-77.
} 
decimales, se aborda la división desde tres casos: decimal entre entero, decimal entre decimal y entero entre decimal. El siguiente párrafo destaca la sugerencia que hace el autor para abordar la multiplicación en el tema «De los números de 100 a $1000 »$; esta muestra dos de los cinco casos propuestos para la exposición de la operación. «El orden que debe seguirse es éste: $1^{\circ}$. - Multiplicación de números dígitos. Para esto se harán repetir los ejercicios de la tabla pitagórica. $2^{\circ}$. - Multiplicación de números compuestos de solo decenas, por un dígito: Cuál es el producto de 30 por 6 ? $»{ }^{60}$

En la tabla 2 se destacan los conceptos asociados a las sugerencias sobre las formas o modos específicos de enseñanza planteados en el libro de texto.

Tabla 2. Conceptos aritméticos vinculados a las indicaciones sobre los modos de enseñanza

\begin{tabular}{|l|l|}
\hline \multicolumn{1}{|c|}{ Indicación } & \multicolumn{1}{|c|}{ Conceptos } \\
\hline \multicolumn{2}{|c|}{ Recursos y materiales } \\
\hline Uso de materiales & $\begin{array}{l}\text { Número, descomposición numérica, suma, resta, } \\
\text { multiplicación, división }\end{array}$ \\
\hline Uso de recursos & $\begin{array}{l}\text { Unidad, cantidad, número, suma (enteros y } \\
\text { quebrados), resta, múltiplos y submúltiplos del metro y } \\
\text { del metro cúbico, superficie, multiplicación (por diez y } \\
\text { sus potencias), fracciones decimales, número } \\
\text { fraccionario, metro (longitud), medidas de capacidad } \\
\text { (litro), antecesor, sucesor, multiplicación, unidad, } \\
\text { decena, centena, división, medidas de peso (gramo). }\end{array}$ \\
\hline \multicolumn{2}{|c|}{ Estrategias para la exposición de contenido } \\
\hline Planificación temática & $\begin{array}{l}\text { Descomposición numérica, multiplicación, suma de } \\
\text { quebrados heterogéneos }\end{array}$ \\
\hline Reseña de contenidos & $\begin{array}{l}\text { Unidad, número, multiplicación, división, quebrado, } \\
\text { máximo común divisor, medidas agrarias, resta }\end{array}$ \\
\hline Secuenciación de tareas & Suma, metro cuadrado (múltiplos), resta, división \\
\hline Procedimientos invariables & Suma \\
\hline
\end{tabular}

${ }^{60}$ Noriega, Manual para el maestro. Curso elemental de aritmética, 77. 
Tabla 2. Conceptos aritméticos vinculados a las indicaciones sobre los modos de enseñanza (cont.)

\begin{tabular}{|l|l|}
\hline \multicolumn{1}{|c|}{ Indicación } & \multicolumn{1}{c|}{ Conceptos } \\
\hline $\begin{array}{l}\text { Adaptación de estrategias } \\
\text { expuestas }\end{array}$ & $\begin{array}{l}\text { Resta de quebrados (a partir de la suma de quebrados), } \\
\text { división de quebrados (división de enteros), suma de } \\
\text { fracciones decimales (suma de enteros), resta de } \\
\text { fracciones decimales (suma de fracciones decimales), } \\
\text { medidas agrarias (aplicación de un cuestionario), } \\
\text { medidas cuadradas del sistema antiguo (medidas } \\
\text { lineales del sistema antiguo) }\end{array}$ \\
\hline $\begin{array}{l}\text { Relaciones entre conceptos } \\
\text { o procedimientos }\end{array}$ & $\begin{array}{l}\text { Resta (con suma), quebrado impropio (resta), } \\
\text { quebrado (división); suma (resta), división } \\
\text { (multiplicación), multiplicación (suma), división } \\
\text { (sustracción), división (suma) }\end{array}$ \\
\hline $\begin{array}{l}\text { Casos particulares para la } \\
\text { resolución de una } \\
\text { operación }\end{array}$ & $\begin{array}{l}\text { Multiplicación de quebrados, división fracciones } \\
\text { decimales, suma, resta, multiplicación, división }\end{array}$ \\
\hline
\end{tabular}

La tabla 2 evidencia el uso de recursos como las indicaciones predominantes para la exposición de diversos conceptos.

En cuanto a las indicaciones sobre las estrategias para la exposición del contenido, estas apuntan, fundamentalmente, a la enseñanza de las operaciones. En este sentido, resaltan la adaptación de procedimientos y las relaciones entre ellos, cuando se abordan las operaciones con distintos tipos de números.

\section{Sobre las proposiciones de evaluación}

En esta categoría se incluyen las indicaciones sobre el seguimiento del aprendizaje del estudiantado, asociadas a tareas propuestas para una evaluación diagnóstica al inicio de la lección y para una evaluación cotidiana que promueve la movilización de conocimientos durante la instrucción. 


\section{Evaluación diagnóstica}

Las recomendaciones sobre algún tipo de evaluación diagnóstica se han identificado en el libro de texto a partir de una indicación particular.

Repaso de conocimientos: se sugiere que al inicio de algunas lecciones se asignen tareas de repaso, esto como un mecanismo para la comprobación de conocimientos previos necesarios para el tema que se desarrollará. En particular, se propone la asignación de ejercicios en los que se realicen divisiones con números hasta 20 , estudiadas en lecciones anteriores, para introducir el tema de la división de los números de 100 a 1000: "Después de algunos ejercicios en que los niños indiquen la midad [sic], tercera, cuarta, etc. partes de los números que les den, se llegará á explicarles más definidamente lo que es la división». ${ }^{61}$

\section{Evaluación cotidiana}

La evaluación cotidiana apunta a distintas comprobaciones y asignaciones durante el desarrollo de las lecciones. Estas se describen a continuación.

Verificación de resultados: el autor recomienda la comprobación de los resultados obtenidos en la resolución de tareas, mediante la relación entre los elementos de las operaciones. Por ejemplo, se propone verificar el resultado de una resta mediante la suma del sustraendo y la diferencia. «Terminada la operación, para probar si está bien hecha, se suma el sustraendo con la diferencia, y la suma debe ser igual al minuendo. Hágase verificar con frecuencia esta prueba, por ser una repetición de la adición». ${ }^{62}$

Repetición de tareas: se sugiere la asignación reiterada de tareas similares, hasta la comprobación de un logro esperado en el estudiantado. «El maestro irá pasando las bolas del alambre para que lo niños las vayan contando. - Ahora, cuenten á la inversa. - Diez, nueve, ... uno. Este ejercicio se repetirá hasta que los niños cuenten con facilidad, tanto en orden ascendente, como en orden descendente».63

\footnotetext{
${ }^{61}$ Noriega, Manual para el maestro. Curso elemental de aritmética, 80.

62 Noriega, Manual para el maestro. Curso elemental de aritmética, 69.

${ }_{63}$ Noriega, Manual para el maestro. Curso elemental de aritmética, 11.
} 
Asignación de tareas: se sugiere que el estudiantado resuelva tareas de forma escrita u oral, asignadas de manera aleatoria $u$ ordenada, de una lista expuesta en el tablero. Por ejemplo, como se sugiere que el estudiantado efectúe algunas tareas en sus pizarras o pasando al tablero, como la mostrada a continuación.

Luégo que las pizarras estén convenientemente colocadas y los niños en aptitud de escribir, el maestro dará las voces de hacia arriba, hacia abajo, UNO; perfil, palote, UNO, y cuidará de que los niños las repitan á medida que escriban. Después se harán salir algunos niños para que escriban el número en el tablero. ${ }^{64}$

Las tareas orales incluyen preguntas explícitas propuestas en el texto, las que proponga el maestro durante la clase y aquellas que surjan del uso de algún material de apoyo que el estudiantado debe responder:

(Conviene dibujar el metro con sus divisiones en el tablero y hacer preguntas sobre el dibujo.)

Siguiendo el camino que queda indicado para dar á conocer el decímetro y las unidades superiores al metro, se enseñará lo que son el centímetro y el milímetro, después de lo cual se formará en el tablero el cuadro de las divisiones y subdivisiones del metro, así:

Un decímetro es la décima parte del metro.

Un centímetro es la centésima parte del "

Un milímetro es la milésima parte del "

Interróguese de varias maneras sobre lo que se acaba de enseñar. ${ }^{65}$

\footnotetext{
${ }^{64}$ Noriega, Manual para el maestro. Curso elemental de aritmética, 15.

${ }_{65}$ Noriega, Manual para el maestro. Curso elemental de aritmética, 115.
} 
Un ejemplo de tareas asignadas de forma aleatoria es el siguiente:

A fin de que los niños no procedan maquinalmente, se cuidará de proponerles la descomposición de números tomados al acaso; pero siempre teniendo la tabla á la vista. Una vez estudiada y comprendida esta tabla, las tareas serán de memoria, primero en el orden indicado arriba, y luégo proponiendo números tomados al acaso. ${ }^{66}$

En la tabla 3 se presentan los conceptos asociados a las sugerencias didácticas propuesta por el autor del libro de texto y reconocidas en la categoría de proposiciones de evaluación.

Tabla 3. Conceptos aritméticos vinculados a las indicaciones sobre las proposiciones de evaluación

\begin{tabular}{|l|l|}
\hline \multicolumn{1}{|c|}{ Indicación } & \multicolumn{1}{c|}{ Conceptos } \\
\hline \multicolumn{1}{|c|}{ Evaluación diagnóstica } \\
\hline Repaso de conocimientos & División \\
\hline \multicolumn{2}{|c|}{ Evaluación cotidiana } \\
\hline Verificación de resultados & $\begin{array}{l}\text { Multiplicación, multiplicación de fracciones } \\
\text { decimales, medidas cúbicas (centímetro cúbico), } \\
\text { suma, resta, división }\end{array}$ \\
\hline Repetición de tareas & $\begin{array}{l}\text { Cantidad, número, multiplicación, fracciones } \\
\text { decimales, división }\end{array}$ \\
\hline Asignación de tareas & $\begin{array}{l}\text { Cantidad, número, metro (longitud), múltiplos y } \\
\text { submúltiplos del metro, superficie, número } \\
\text { fraccionario, quebrado impropio, multiplicación de } \\
\text { quebrados, medidas de peso (gramo), medidas } \\
\text { agrarias, medidas de capacidad (leña y madera), } \\
\text { antecesor y sucesor, unidad, decena y centena, suma, } \\
\text { resta, división, descomposición numérica, } \\
\text { multiplicación, medidas cúbicas }\end{array}$ \\
\hline
\end{tabular}

La información en la tabla 3 muestra que la división es el único concepto para el que se sugiere el repaso de conocimientos, con tareas basadas en «partir» en partes iguales una cantidad, con el propósito de

${ }^{66}$ Noriega, Manual para el maestro. Curso elemental de aritmética, 22. 
comprobar conocimientos previos útiles para la exposición y comprensión de esta operación.

En cuanto a las tres indicaciones sobre evaluación cotidiana: verificación de resultados, repetición de tareas y asignación de tareas, los conceptos considerados se enlazan principalmente a la exposición de operaciones, unidades de medida y tipos de números. Destaca la asignación de tareas como indicación durante el abordaje de temas específicos.

Finalmente, el análisis llevado a cabo, a partir de la información en el libro de texto y las categorías consideradas, permite emitir una serie de conclusiones. Estas toman como base los conceptos matemáticos y las sugerencias didácticas reconocidas en el libro de texto analizado.

\section{CONCLUSIONES}

El estudio ha pretendido una caracterización de las sugerencias didácticas propuestas para la enseñanza de la aritmética en educación primaria, presentadas en documentos curriculares editados en Costa Rica, a finales del siglo XIX, para la formación de maestros en las denominadas Secciones Normales. Para esto, se analizó el libro de texto: el Manual para el maestro. Curso elemental de aritmética de Félix F. Noriega, editado en 1897.

El análisis llevado a cabo incluyó la descripción de los conceptos aritméticos, la identificación y clasificación de las sugerencias mostradas en el texto, a partir de los principios del análisis didáctico, que resaltan aspectos cognitivos, de instrucción y evaluación, sin dejar de lado las especificidades conceptuales y procedimentales. ${ }^{67}$

Las conclusiones del estudio se han organizado desde aspectos generales, para luego acentuar las particularidades obtenidas del proceso de investigación a partir de las categorías de análisis.

Desde un marco general e histórico, a pesar de las iniciativas para la formación de maestros, que derivaron en la creación de escuelas normales, desde la perspectiva de la organización educativa, las instituciones de educación secundaria constituyeron un soporte para la formación de

\footnotetext{
${ }^{67}$ Rico y Fernández-Cano, «Análisis didáctico y metodología de investigación», 1-22.
} 
maestros en Costa Rica, como los centros que albergaron los procesos de preparación temprana de docentes de educación primaria, en los siglos XIX y XX.

A finales del siglo XIX, la formación de maestros en Costa Rica estuvo basada en una formación complementaria de la educación secundaria, impartida en las Secciones Normales. En concordancia con Edwin León, ${ }^{68}$ esta formación carecía — desde un punto de vista actual— de un plan curricular basado en la ciencia y la pedagogía. Sin embargo, esta limitación impulsó, junto con otros aspectos, la creación de la Escuela Normal de Costa Rica como el centro de estudios para la especialización y certificación profesional de los maestros, con la titulación de «Maestro Normal».

La enseñanza de la aritmética en Costa Rica durante el siglo XIX puede caracterizarse por un abordaje progresivo de conceptos y procedimientos. El conteo y la numeración constituyeron los conocimientos aritméticos prioritarios en el adiestramiento de los pobladores en las escuelas de primeras letras. Con la creación de la Casa de Enseñanza de Santo Tomás, el estudio de la aritmética se fortaleció con la inclusión de un mayor número de contenidos matemáticos, que contribuyó con el progreso y la calidad de la educación que se pretendían para los ciudadanos después de la independencia.

En cuanto al libro de texto, se precisa que constituyó una fuente oficial de consulta del maestro para la enseñanza de la aritmética en los primeros cuatro años de la educación primaria. Su elaboración respondió a la necesidad de contar con un texto que estructurara la enseñanza de la aritmética y consideró el método socrático, que fomenta el uso ordenado y reiterado de preguntas y respuestas para el aprendizaje. En palabras del autor, «cuyo éxito [de este método] está basado no solamente en la claridad y buena condición de las preguntas, sino también en el orden en que se hagan».69 Además, se fundamentó en planteamientos de autores extranjeros en esta área. Se presume que el autor pudo tomar en consideración obras como la Nueva aritmética para las escuelas primarias

\footnotetext{
68 Edwin León, Una universidad en una ciudad de maestros (Heredia: Departamento de Publicaciones de la Universidad Nacional, 1982).

69 Noriega, Manual para el maestro. Curso elemental de aritmética, 6-7.
} 
dividida en dos partes del francés G. Ritt (1887), los Elementos de aritmética y geometría para escuelas primarias (1884) o La enseñanza de la aritmética y la geometría en las escuelas primarias (1887) del francés F. Vintejoux; y hacer referencia al pedagogo alemán Alberto Blume, encargado de la organización de las Escuelas Normales en Colombia.

De esto, se puede afirmar que este libro de texto es una evidencia de la influencia de ideas y propuestas extranjeras, mediante el aporte de un autor foráneo a la educación matemática costarricense en el siglo XIX y una muestra de las iniciativas para mejorar la calidad de la educación matemática y la formación de maestros en Costa Rica, antes de la fundación de la Escuela Normal.

Para lo que sigue, es necesario recordar que se han considerado como sugerencias didácticas aquellas indicaciones específicas, vinculadas a conceptos aritméticos, que resaltan particularidades del aprendizaje del estudiantado, diversas formas de enseñanza y proposiciones para la evaluación; estos tres tipos de indicaciones corresponden a las categorías generales que se definieron para el análisis y orientan la presentación de las siguientes conclusiones.

En cuanto a los aspectos cognitivos sobre el aprendizaje del estudiantado, las tareas presentadas en el libro de texto para el abordaje de los conceptos aritméticos se caracterizan por su cantidad, diversidad e intencionalidad.

La exposición de tareas combina propósitos memorísticos y aquellos que conducen a la comprensión de conceptos, sobresaliendo el primero para la presentación de conceptos y procedimientos específicos. En este sentido, a partir de lo propuesto por el autor, se identifican dos etapas de aprendizaje: la primera basada en la memoria, complementada con el cálculo mental; y la segunda dirigida al desarrollo de capacidades, a partir de la exposición de argumentos por parte del estudiantado.

En cuanto a las sugerencias para advertir sobre dificultades de aprendizaje, estas tienen poca presencia en el texto; no obstante, las que se muestran proponen al lector —en este caso el maestro- el uso de tareas específicas para atender las posibles dificultades que pueda mostrar el estudiantado durante el aprendizaje de conceptos y procedimientos aritméticos. 
Las tareas propuestas para el aprendizaje se caracterizan por un fuerte componente de contextualización; los fenómenos mostrados en estas se vinculan al entorno inmediato del estudiantado en la época, que enfatizan, por ejemplo, situaciones comerciales, personales y sociales. Aunado a esto, durante el aprendizaje se promueve evitar el desinterés del estudiantado, mediante la presentación de una cantidad reducida de tareas. El uso frecuente de tareas orales concuerda con el método socrático utilizado en el texto para la presentación de contenidos aritméticos.

Por último, la mayoría de las sugerencias didácticas vinculadas a aspectos cognitivos están dirigidas al aprendizaje de las operaciones aritméticas, con especial atención a la suma y la división.

En el componente de instrucción, las sugerencias se orientan al uso constante de medios para la enseñanza, es decir, materiales y recursos didácticos que se proponen al maestro en el texto para apoyar este proceso. Particularmente, los materiales son sugeridos para la exposición de información; y los recursos para la introducción y el desarrollo de distintos temas, destacando la utilización de objetos concretos.

En general, los medios propuestos para la enseñanza —entendidos como materiales y recursos- se asocian a la introducción de un concepto y al adiestramiento en la realización de operaciones aritméticas. Se enfatiza su uso para presentar conceptos como cantidad, unidad, número, aquellos asociados al Sistema Métrico Decimal y las operaciones; las sugerencias otorgan un énfasis especial a la implementación de objetos concretos y recursos.

La presentación de procedimientos invariables sustenta, en una primera etapa de aprendizaje, la afirmación sobre el predominio del aprendizaje memorístico sobre aquel basado en el fomento de capacidades. Sin embargo, la diversidad de situaciones mostradas en las tareas proporciona un co-protagonismo al desarrollo de capacidades, desde la aplicación de conceptos y procedimientos aritméticos.

Las indicaciones para exponer los contenidos se vinculan a la enseñanza de las operaciones con distintos números, dando un papel predominante a las sugerencias relacionadas con la adaptación de estrategias implementadas en otros momentos de la enseñanza, las relaciones entre 
conceptos y a los casos particulares que pueden presentarse al resolver una tarea.

La reseña de contenidos y la secuenciación de tareas, destacan como sugerencias para la exposición de contenidos que se aplican a nivel general en el texto, esto es, sin importar el contenido que se pretende abordar.

El desarrollo de algunos temas considera el grado de complejidad del concepto o procedimiento que incide en que se sugiera una distribución temporal para su enseñanza. Aunado a esto, para el agrupamiento del estudiantado durante las lecciones, se fomenta el trabajo individual o del grupo completo, mediante la participación de estudiantes que el maestro selecciona o la asignación de tareas para que todo el colectivo resuelva, respectivamente; no se reconocen sugerencias que promuevan el trabajo en grupos pequeños de estudiantes. En concordancia con Flores, Gómez y Marín, ${ }^{70}$ el trabajo en gran grupo permite la presentación de materia, la conducción de debates y la realización de preguntas; la organización individual del estudiantado contribuye a la resolución de problemas y la memorización. Estos aspectos concuerdan con los propósitos de las etapas de aprendizaje identificadas: la memorización y el desarrollo de capacidades.

En cuanto a las proposiciones de evaluación, a pesar de reconocerse la evaluación diagnóstica como un tipo de comprobación de conocimientos, previa a la presentación de determinados conceptos, esta no constituye un componente sobresaliente en las propuestas evaluativas en el libro de texto.

El desarrollo de los temas se complementa con la asignación de tareas que, además de procurar un adiestramiento en determinados procedimientos, tienen el propósito de mostrar al maestro el grado de avance del estudiantado en la memorización o comprensión de conceptos.

En el libro de texto se presentan listas de tareas al final de la mayoría de las lecciones, sin una indicación previa de su intencionalidad. Sin embargo, estas se entienden como un insumo que el maestro puede utilizar durante el proceso de enseñanza o como evaluaciones de carácter formativo.

\footnotetext{
${ }^{70}$ Pablo Flores, Pedro Gómez y Antonio Marín, Apuntes sobre análisis de instrucción. Módulo 4 de MAD (Bogotá: Universidad de los Andes, 2013). http://funes.uniandes.edu.co/2061/
} 
Las estrategias de evaluación que se reconocen en el libro de texto incentivan la participación oral y escrita del estudiantado. En este sentido, la participación oral se dirige a la repetición de nombres, definiciones o valores conocidos, característica del método socrático; por su parte, la participación escrita fomenta el desarrollo de destrezas de escritura, la resolución de operaciones mediante la aplicación de conceptos y procedimientos.

En general, las sugerencias evaluativas propuestas en el texto pretenden determinar si el estudiantado tiene los conocimientos necesarios para aprender un nuevo tema o bien verificar si ha logrado adquirir las capacidades que se pretendían desarrollar, principalmente sobre contenidos relacionados con las operaciones aritméticas y el Sistema Métrico Decimal.

Por último, debe destacarse que el libro de texto analizado sobresale por la cantidad de sugerencias didácticas que se proponen al maestro para la enseñanza de la aritmética en la Educación Primaria; estas consideraban aspectos propios del aprendizaje del estudiantado, de la gestión de aula y de los procesos para valorar la adquisición del conocimiento.

\section{Nota sobre los autores}

Miguel Picado es Doctor en Didáctica de la Matemática por la Universidad de Granada, España, y Licenciado en Enseñanza de la Matemática por la Universidad Nacional de Costa Rica. Mi afinidad y experiencia con la investigación se asocia a la Historia de la Educación Matemática, destacando el análisis de libros de texto históricos para el estudio de conceptos matemáticos vinculados al Sistema Métrico Decimal, desde una perspectiva matemática y didáctica; y la Formación de Profesores de Matemática, que enmarca los estudios llevados a cabo sobre el conocimiento matemático para la enseñanza manifestado por el docente en ejercicio al enseñar conceptos matemáticos vinculados a la Función. Formo parte del equipo editor de la revista PNA, del Departamento de Didáctica de la Matemática de la Universidad de Granada, y del equipo editor de la revista UNICIENCIA, de la Facultad de Ciencias Exactas y Naturales de la Universidad Nacional de Costa Rica. He participado en eventos académicos y científicos a nivel internacional como el Simposio de la Sociedad Española de Investigación en Educación Matemática (SEIEM), la Conferencia Internacional sobre Historia de la Educación 
Matemática (ICHME), la Conferencia Interamericana de Educación Matemática (CIAEM), el Congreso Iberoamericano de Historia de la Educación Matemática (CIHEM) y la Reunión Latinoamericana de Matemática Educativa (RELME).

Jonathan EsPinoza es Máster en Didáctica de la Matemática por la Universidad de Granada, España, y Licenciado en Enseñanza de la Matemática por la Universidad Nacional de Costa Rica. Mi experiencia como investigador en Educación Matemática se vincula con tres líneas de investigación: Historia de la Educación Matemática, como participante del proyecto de investigación «La formación matemática de los maestros y maestras en la Escuela Normal de Costa Rica: el caso de la Aritmética» que se realiza actualmente en la Escuela de Matemática de la Universidad Nacional; Formación de profesores, como participante del proyecto de investigación «Conocimiento matemático para la enseñanza de las funciones de dos profesores en el ciclo diversificado de la Educación Matemática en Costa Rica» realizado en la Escuela de Matemática de la Universidad Nacional desde el año 2014 y hasta 2016; y Didáctica de la Estadística y la Probabilidad, particularmente el análisis del desarrollo de la Combinatoria en libros de texto de Educación Secundaria en España y la enseñanza de la Estadística mediante la metodología de resolución de problemas. También participé en el proyecto «Reforma de la Educación Matemática en Costa Rica» del Ministerio de Educación Pública y auspiciado por la fundación Costa Rica-Estados Unidos para la Cooperación (CRUSA), el cual diseñó e implementó los nuevos programas de estudio de Matemática para la Educación preuniversitaria. He participado en eventos académicos a nivel internacional como la Reunión Latinoamericana de Matemática Educativa (RELME) y el Simposio de Educación Matemática (SEM) que se realiza en la Ciudad de Chivilcoy, Argentina.

\section{REFERENCIAS}

Agüero, Ana, Marta Baires, Marycruz Murillo y Lourdes Ulate. «Experiencias educativas de los formadores de docentes en la Escuela Normal de Costa Rica (1951-1973). “Lecciones del pasado”». D diss., Universidad Nacional, 2008.

Aróstegui, Julio. La investigación histórica: teoría y método. Barcelona: Crítica, 2001. 
Best, John W. ¿Cómo investigar en educación?. Madrid: Morata, 1982.

Bjarnadóttir, Kristín, Fulvia Furinghetti, Marta Menghini, Johan Prytz, y Gert Schubring. "Dig Where you Stand» 4. Proceedings of the Fourth International Conference on the History of Mathematics Education. Roma: Edizioni Nuova Cultura, 2017.

Cardoso, Ciro. Introducción al trabajo de la investigación histórica: conocimiento, método e historia. Barcelona: Crítica, 2000.

Carrillo, Dolores. La metodología de la aritmética en los comienzos de las Escuelas Normales (1838-1868) y sus antecedentes. Murcia: Universidad de Murcia, 2005.

Cohen, Louis y Lawrence Manion. Métodos de Investigación Educativa. $2^{\mathrm{a}}$ ed. Madrid: La Muralla, 2002.

De la Cruz, Vladimir. «La educación y la cultura costarricense en el siglo XIX: de las Cortes de Cádiz a las Reformas educativas». En Historia de la educación costarricense, editado por Jorge Mario Salazar, 1-71. San José: EUNED, 2003.

Dengo, María Eugenia. Educación costarricense. San José: Editorial Universidad Estatal a Distancia, 2011.

Fishel, Astrid. "La educación costarricense: entre el liberalismo y el intervencionismo». En Historia de la Educación Costarricense, editado por Jorge Mario Salazar, 73-115. San José: EUNED, 2003.

Flores, Pablo, Pedro Gómez y Antonio Marín. Apuntes sobre análisis de instrucción. Módulo 4 de MAD. Bogotá: Universidad de los Andes, 2013. http://funes.uniandes.edu.co/2061/

Fox, David. El proceso de investigación en educación. Pamplona: Universidad de Navarra, 1987.

González, Luis Felipe. Historia de la influencia extranjera en el desenvolvimiento educacional y científico de Costa Rica. San José: Imprenta Nacional, 1921.

González-Arrieta, Ruth y Xinia Moya-López. «Libros de la Universidad de Santo Tomás preservados en la Biblioteca Nacional». Bibliotecas 34 (2016): 5993. DOI: http://dx.doi.org/10.15359/rb.34-2.3

González, María Teresa. «Sistemas simbólicos de representación en la enseñanza del análisis matemático: perspectiva histórica acerca de los puntos críticos». PhD diss., Universidad de Salamanca, 2002.

Le Goff, Jacques. Pensar la Historia. Modernidad, presente, progreso. Barcelona: Paidós, 2011.

León, Edwin. Una universidad en una ciudad de maestros. Heredia: Departamento de Publicaciones de la Universidad Nacional, 1982.

López, Carmen. «La formación inicial de maestros en aritmética y álgebra a través de los libros de texto». PhD diss., Universidad de Salamanca, 2011.

Losee, John. Filosofía de la ciencia e investigación histórica. Madrid: Alianza, 1989. 
Malavassi, Guillermo y Pedro Gutiérrez. Diccionario biográfico de Costa Rica. San José: Universidad Autónoma de Centro América, 1992.

Martínez, Bernal. Cronología de la educación costarricense. San José: Imprenta Nacional, 2016.

Maz, Alexander. "Los números negativos en España en los siglos XVIII y XIX». PhD diss., Universidad de Granada, 2005.

Noriega, Félix F. Manual para el maestro. Curso elemental de aritmética, arreglado de acuerdo con los programas oficiales. San José: Imprenta Comercial, 1897.

Osejo, Rafael. Brebes lecciones de arismetica para el uso de los alunnos de la Casa de Sto. Tomás. San José: Imprenta de La Paz, 1830.

Picado, Miguel. «El Sistema Métrico Decimal en libros de texto de matemáticas en España durante la segunda mitad del siglo XIX (1849-1892)». PhD diss., Universidad de Granada, 2012.

Picado, Miguel y Luis Rico. "Análisis de contenido en textos históricos de matemáticas». PNA 6, no. 1 (2011): 11-27. http://hdl.handle.net/10481/16013

Picado, Miguel y Luis Rico. "La selección de textos en una investigación histórica en educación matemática». Épsilon 77, no. 1 (2011): 99-112. https://thales.cica.es/epsilon/sites/thales.cica.es.epsilon/files/epsilon77.pdf Quesada, Juan Rafael. Un siglo de educación costarricense 1814-1914. San José: Editorial de la Universidad de Costa Rica, 2005.

Rico, Luis y Antonio Fernández-Cano. «Análisis didáctico y metodología de investigación». En Análisis Didáctico en Educación Matemática. Metodología de investigación, formación de profesores e innovación curricular, editado por Luis Rico, José L. Lupiáñez y Marta Molina, 1-22. Granada: Comares, 2013.

Rodríguez, Pedro y Ángel Ruíz. "Antes de la Reforma de Mauro Fernández». En Historia de las matemáticas en Costa Rica, editado por Ángel Ruíz, 22-34. San José: EUCR/EUNA, 1994.

Salazar, Carlos Francisco. Curso de aritmética razonada. San José: Imprenta Nacional, 1885.

Salkind, Neil J. Métodos de investigación. Ciudad de México: Prentice-Hall, 1999. Schubring, Gert. "On the Methodology of Analysing Historical Textbooks: Lacroix as textbook author». For the Learning of Mathematics 7, no. 3 (1987): 41-51. https://flm-journal.org/index.php?do=show\&lang=en\&showMenu=7\%2C3

Schubring, Gert. «Categorías teóricas para la investigación en la historia social de la enseñanza de la matemática y algunos modelos característicos». Épsilon 19 (1991): 100-104. https://thales.cica.es/epsilon/?q=content/epsilon-n\%C2\%BA-77-a\%C3\%B1o-2011-volumen-28-1

Suárez, Federico. La historia y el método de investigación histórica. Madrid: Rialp, 1977.

Zeledón, Elías. Crónicas para la historia de la educación costarricense. Desde sus orígenes hasta la creación de la Universidad de Costa Rica. San José: EUNED, 2014. 